\title{
Inappropriate secretion of antidiuretic hormone in infants with respiratory infections
}

\author{
RODNEY P A RIVERS, MARY L FORSLING, AND RICHARD P OLVER \\ Department of Paediatrics, University College Hospital Medical School, and Department of Physiology, \\ Middlesex Hospital Medical School
}

SUMMARY Four infants in whom excessive secretion of antidiuretic hormone was associated with pulmonary infections are reported. Severe hyponatraemia was noted in 3 of them; in the fourth, fluid restriction may have prevented this complication.

In several reports associations have been noted between the excessive secretion of antidiuretic hormone (ADH) and disorders encountered in the neonatal period and in later childhood. Those in which pulmonary disorders have been implicated include viral and bacterial pneumonias, ${ }^{1-5}$ pneumothorax and atelectasis, ${ }^{6}$ acute asthmatic attacks, ${ }^{78}$ and lung distension during continuous positive airways pressure (CPAP) administration and mechanical ventilation ${ }^{9}$ (although some of the neonates in the last-mentioned series also had intracranial disease).

This report draws attention to the consequences of excessive secretion of ADH in association with common pulmonary infections in infancy. The severity and rapidity of development of hyponatraemia that resulted in 3 of the cases is noteworthy. In the fourth case, prospective therapeutic measures may have prevented the development of this complication. Possible mechanisms for increased ADH secretion are discussed and therapeutic approaches considered.

\section{Patients and methods}

Four infants were admitted during a local outbreak of respiratory syncytial virus (RSV)-positive bronchiolitis and pneumonia. All manifested evidence of increased secretion of ADH.

RSV was identified by immunofluorescence and by culture of material obtained by aspiration of pharyngeal washes. ${ }^{10} 11$

ADH was assayed in plasma by radioimmune assay. ${ }^{12} 13$ Urine osmolality was measured by freezing point depression, specific gravity by $T S$ refractometer (American Optical), and biochemical estimations by routine laboratory procedures. Blood gases were analysed in heparinised arterial blood using Radiometer equipment.

\section{Case reports}

Case 1. A 6-week-old formula-fed girl, presented with a 4-day history of increasing respiratory difficulty, cough, partial feed refusal, and sleeplessness. She had vomited twice 2 days before admission; there had been no diarrhoea. On the day of admission her parents noted that she felt stiff when handled and earlier that day she had had a grand mal seizure lasting about 30 minutes.

\section{Examination}

Grunting, dyspnoeic, with increased respiratory rate; expiratory rhonchi and fine crepitations were present over both lung fields. She was not apparently dehydrated. A focal left-sided seizure began shortly after admission. The ensuing apnoea necessitated endotracheal intubation and ventilation for 30 minutes.

\section{Investigations}

Normal plasma urea, sugar, calcium, magnesium, cerebrospinal fluid, electrocardiogram, and skull radiograph. Chest radiograph showed translucent hyperinflated lungs. Plasma sodium $121 \mathrm{mmol} / \mathrm{l}$, urine osmolality $275 \mathrm{mmol} / \mathrm{kg}$. Blood gas analysis: $\mathrm{PaO}_{2} 5 \cdot 1 \mathrm{kPa}\left(38 \mathrm{mmHg}\right.$ ), and $\mathrm{PaCO}_{2} 6 \cdot 8 \mathrm{kPa}$ $(45 \mathrm{mmHg}$ ) breathing air spontaneously before intubation. Immunofluorescence for RSV was positive.

Course. Treated with digoxin, anticonvulsants, and oxygen and, initially, with antibiotics. 
A rise in plasma sodium concentration to 134 $\mathrm{mmol} / \mathrm{l}$ was achieved in 12 hours in association with improved oxygenation, fluid restriction $(100 \mathrm{ml} / \mathrm{kg}$ in 24 hours), and administration of hypertonic (270 mmol/l) sodium chloride followed by $0.9 \%$ sodium chloride. Urine sodium excretion occurred concurrently and equalled $11 \mathrm{mmol}$ of the $57 \mathrm{mmol}$ infused in 24 hours. $\mathrm{PaCO}_{2}$ was normal within 48 hours and oxygen supplementation was stopped after 72 hours. The infant subsequently was shown to have a normal electroencephalogram; a synacthen stimulation test induced normal cortisol release.

Case 2. A 7-week-old breast-fed boy presented with history of nasal obstruction for 4 days. He had become irritable in association with rapid breathing for 2 hours before admission. There was no diarrhoea.

\section{Examination}

Tachycardia $156 /$ minute, grade $2 / 6$ apical systolic murmur; respirations $36 /$ minute, no added sounds in chest. Nasal secretions increased. Liver and spleen were not palpable. After 36 hours the respiratory rate had increased to 130 per minute, and the liver and spleen were palpable.

\section{Investigations}

Chest radiograph showed translucent markedly hyperinflated lungs with depressed diaphragm.

Treatment. Digoxin, a single dose of frusemide $1 \mathrm{mg} / \mathrm{kg}$, fluid restriction $(100 \mathrm{ml} / \mathrm{kg}$ in 24 hours $)$, and oxygen.

Course. Forty-eight hours after admission diffuse fine crepitations were audible over both lung fields. Plasma sodium was normal $(135 \mathrm{mmol} / \mathrm{l})$ at this time. Twelve hours later plasma sodium had fallen to $124 \mathrm{mmol} / \mathrm{l}$ in association with an inappropriately concentrated urine $(534 \mathrm{mmol} / \mathrm{kg})$ (Table 1). Pulmonary gas exchange had deteriorated, $\mathrm{PaO}_{2}$ $6.4 \mathrm{kPa}(48 \mathrm{mmHg})$ in $\mathrm{F}_{1} \mathrm{O}_{2} 0.21, \mathrm{PaCO}_{2} 9.1 \mathrm{kPa}$ $(68 \mathrm{mmHg})$. Further treatment consisted of greater fluid restriction (50 ml/kg in 24 hours), ampicillin, and continued oxygen supplementation. The course of the illness is shown in Fig. 1. During the next 4 days brief periods of increased fluid intake were associated with falls in plasma sodium concentration, and progressive hypertension was noted. Resolution of electrolyte disturbance took place after 5 days, with the fall in urine concentration occurring during continued fluid restriction. Immunofluorescence for RSV on day 3 of the respiratory illness was negative.

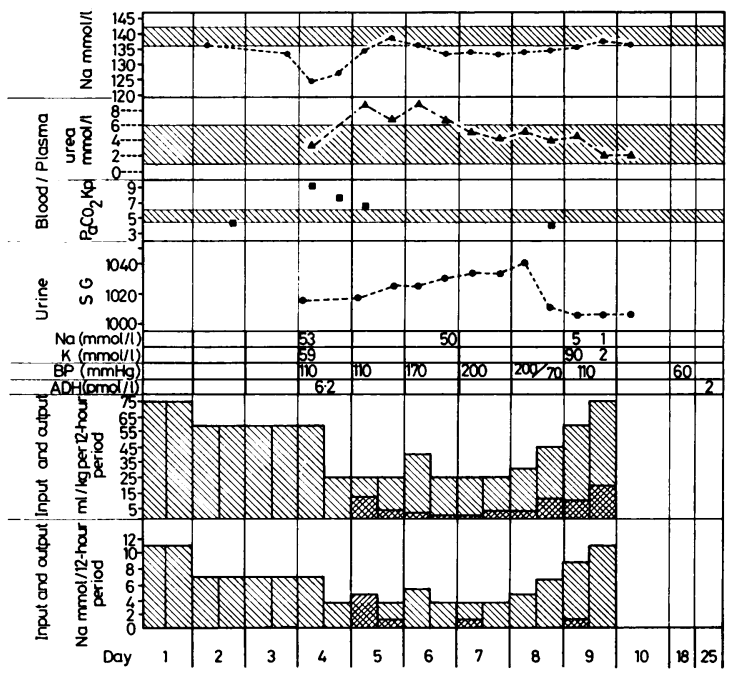

Fig. 1 (Case 2.) Flow diagram of clinical course. Hyponatraemia developed on day 4 of respiratory illness at the peak of recorded hypercarbia in association with production of a non-maximally dilute urine, inappropriately high antidiuretic hormone level, and natriuresis. Fluid restriction was associated with a rise in plasma sodium, urea, and blood pressure. The diminution in urine concentration on day 8 occurred during continued fluid restriction and represents excretion of body water derived from body tissue catabolism and fluid intake, previously retained under the influence of excessive antidiuretic hormone secretion.

Table 1 Results of investigations in Cases 1-4

\begin{tabular}{|c|c|c|c|c|c|c|c|c|}
\hline \multirow[t]{2}{*}{ Case } & \multicolumn{2}{|l|}{ Plasma } & \multicolumn{2}{|l|}{ Urine } & \multicolumn{2}{|l|}{ Body weight $(\mathrm{kg})$} & \multicolumn{2}{|c|}{$A D H(\mathrm{pmol} / \mathrm{l})(0.96-3.60)$} \\
\hline & $\begin{array}{l}\mathrm{Na} \\
(\mathrm{mmol} / \mathrm{l})\end{array}$ & $\begin{array}{l}\text { Urea } \\
(\text { mmol/l) }\end{array}$ & $\begin{array}{l}\mathrm{Na} \\
(\mathrm{mmol} / \mathrm{l})\end{array}$ & $\begin{array}{l}\text { Osmolality } \\
(\mathrm{mmol} / \mathrm{kg})\end{array}$ & $\begin{array}{l}\text { At diagnosis of } \\
\text { hyponatraemia }\end{array}$ & $\begin{array}{l}\text { On recovery from } \\
\text { hyponatraemia }\end{array}$ & $\begin{array}{l}\text { During respiratory } \\
\text { distress }\end{array}$ & On recovery \\
\hline $\begin{array}{l}1 \\
2 \\
3 \\
4\end{array}$ & $\begin{array}{l}121 \\
124 \\
114 \\
137\end{array}$ & $\begin{array}{l}2 \cdot 5 \\
3 \cdot 5 \\
4 \cdot 2 \\
2 \cdot 5\end{array}$ & $\begin{array}{r}34 \\
53 \\
3 \\
28\end{array}$ & $\begin{array}{l}275 \\
534 \\
243 \\
474\end{array}$ & $\begin{array}{l}4 \cdot 075 \\
4 \cdot 900 \\
2 \cdot 980 \\
6 \cdot 400\end{array}$ & $\begin{array}{l}3 \cdot 800 \\
4 \cdot 800 \\
2 \cdot 960 \\
6 \cdot 500\end{array}$ & $\begin{array}{l}\overline{6 \cdot 24} \\
\overline{7 \cdot 20}\end{array}$ & $\begin{array}{l}\overline{2.40} \\
\overline{1.68}\end{array}$ \\
\hline
\end{tabular}

Lowest values of plasma sodium concentrations are shown; these occurred within 4 days of onset of pulmonary symptoms. Urine osmolalities are inappropriately high in all cases. There is no evidence of dehydration either from plasma urea values or on the basis of bodyweight measurements made at the time of hyponatraemia compared with those recorded on recovery. 
Case 3. A girl, the second of twins born at 32 weeks' gestation weighing $1.69 \mathrm{~kg}$, had developed transient tachypnoea in the neonatal period At age 8 weeks she became unwell with feed refusal and nasal obstruction, and within 24 hours developed rapid respiration of 60/minute and a tachycardia of $190 /$ minute; there were fine crepitations over both lung fields. Chest radiograph showed right upper lobe consolidation. Within 48 hours of onset, pulmonary function deteriorated, $\mathrm{PaO}_{2} 6.0 \mathrm{kPa}(45 \mathrm{mmHg})$, $\mathrm{F}_{\mathrm{I}} \mathrm{O}_{2} 0 \cdot 30, \mathrm{PaCO}_{2} 6 \cdot 7 \mathrm{kPa}(50 \mathrm{mmHg})$. She began convulsing.

Further investigations showed normal plasma calcium, sugar, urea, and cerebrospinal fluid, but marked hyponatraemia $(114 \mathrm{mmol} / \mathrm{l})$ and less than maximally dilute urine $(243 \mathrm{mmol} / \mathrm{kg})$ (Table 1$)$.

Treatment. She was ventilated for 24 hours, fluids were restricted $(42 \mathrm{ml} / \mathrm{kg}$ in 24 hours), and she was given sodium supplements $(7 \mathrm{mmol} / \mathrm{kg}$ per day) and antibiotics. An immediate improvement was obtained. Plasma sodium concentration rose to $130 \mathrm{mmol} / \mathrm{l}$ within 24 hours and urine osmolality fell to $195 \mathrm{mmol} / \mathrm{kg}$ during this period of fluid restriction. RSV was cultured from pharyngeal aspirate.

Case 4. A 6-month-old formula-fed boy presented with a 24-hour history of cough, blocked nose, and breathlessness.

\section{Examination}

Tachypnoea (80/minute), fine crepitations and expiratory rhonchi were present over both lung fields. Liver and spleen were palpable.

\section{Investigations}

Normal arterial blood gases, electrolytes, and urea. Chest radiograph showed translucent hyperinflated lungs. Immunofluorescence for RSV was positive.

Treatment. Fluid restriction (100 ml/kg in 24 hours), ampicillin initially.

Course. Increasing dyspnoea over first 24 hours. Plasma sodium ranged from 137 to $139 \mathrm{mmol} / \mathrm{l}$ during 5 days of respiratory symptoms.

During the period of maximum respiratory difficulty both the plasma ADH level $(7 \cdot 20 \mathrm{pmol} / \mathrm{l})$, and urine osmolality $(474 \mathrm{mmol} / \mathrm{kg})$ were increased. Within 24 hours the urine osmolality had fallen $(164 \mathrm{mmol} / \mathrm{kg})$ and remained at between 126 and $164 \mathrm{mmol} / \mathrm{kg}$ with the infant receiving $100 / \mathrm{ml}$ per $\mathrm{kg}$ during 4 days of improving respiratory status (Table 1). By this time the ADH level had fallen to
$1.68 \mathrm{pmol} / \mathrm{l}$. Body weight did not vary beyond the range $6400-6600 \mathrm{~g}$ during the first 7 days after admission.

\section{Discussion}

The physiology of ADH was reviewed by Hays. ${ }^{14}$ ADH is believed to be released into the plasma from its site of storage in the posterior pituitary gland in response to the following stimuli: an increase in extracellular fluid osmolality, ${ }^{15} 16$ reduction in intravascular fluid volume ${ }^{17}$ as reflected by a reduction in tension in the wall of the left atrium, ${ }^{18} 19$ and stimulation of pressor receptors in the carotid sinus. ${ }^{20}$ Beta sympathomimetic drugs and stress itself also stimulate ADH release. ${ }^{21}{ }^{22}$ Acting via adenylate cyclase and cyclic-AMP, ADH renders the distal renal tubules and collecting ducts permeable to water, urea, and other solutes. ${ }^{23}{ }^{24}$ Reabsorption at these sites depends on the existing concentration gradients from tubule to interstitium.

From these considerations, it is evident that should a local change, which normally respresents a physiological stimulus for ADH release, fail to be a true reflection of the overall osmotic or circulatory status of an individual, ADH release may occur with undesirable consequences. Then the release may be excessive for the body's requirements. If release occurs in the absence of any physiological stimulus, it may be regarded as inappropriate. The consequences of these two situations may be similar with the development of a hyponatraemic, hypo-osmolar state as first described in association with ADHsecreting carcinomata of the bronchus. ${ }^{25}$ That syndrome of inappropriate ADH secretion (SIADH) is manifested by hyponatraemia in combination with the excretion of a urine which is not maximally dilute in the absence of dehydration, blood volume depletion, or abnormal adrenal function. ${ }^{26}$ Continued natriuresis may be observed.

In all 3 infants with hyponatraemia, the low plasma sodium level was related to severe pulmonary dysfunction as shown by hypoxaemia and hypercarbia. Neither on clinical evidence nor on the basis of biochemical and sequential body weight measurements was dehydration present. The clinical history of Case 1, and measured fluid intakes of Cases 2 and 3 , indicated that there had been no excessive fluid intake during the 24 hours preceding the detection of hyponatraemia, neither had there been any apparent abnormal fluid losses. In Cases 1 and 3, who had been on free fluids, intake was below normal because of feed refusal. It is noteworthy that Case 2 became hyponatraemic despite fluid restriction $(100 \mathrm{ml} / \mathrm{kg}$ per day) whereas this degree of restriction was 
sufficient to prevent hyponatraemia in Case 4. In Cases 2 and 4, the level of ADH was found to be increased in the acute phase (Table 1).

In Cases 1, 2, and 3 the urine solute concentrations were inappropriately high for the degree of plasma hypotonicity present (Table 1). During the period of maximal hyponatraemia, measured total cation excretion was low in all cases. Whereas in Cases 1 and 2, small volumes of urine with high concentrations of sodium and potassium were excreted, in Case 3 (the most severely hyponatraemic) urine sodium concentration was low. Aldosterone secretion has been shown to continue once a new steady state is reached in SIADH so that sodium excretion reflects intake. ${ }^{27}$ Absence of continued natriuresis in the presence of sodium deprivation in SIADH has been noted previously. ${ }^{28}$

Despite the high degree of correlation between serum sodium concentration and the ratio of the sum of the total body exchangeable sodium and potassium to total body water in normal individuals, it has not been possible to account for the degree of hyponatraemia induced by acute water loading on the basis of urinary cation ( $\mathrm{Na}$ and $\mathrm{K}$ ) loss and body water gain in cases where ADH is being excessively secreted. ${ }^{28-30}$ Attention has also been drawn ${ }^{28}$ to the lower than predicted rise in plasma sodium after sodium administration in SIADH. Explanations have invoked the concept of an altered body sodium and potassium distribution, and a low total body exchangeable potassium with increased muscle sodium content has been reported. ${ }^{30-32}$

Of interest in this regard are the observations on sodium and potassium balance in Case 1. During the hyperosmolar sodium chloride administration, balance studies indicated that between 12 and $19 \mathrm{mmol}$ sodium remained unaccounted for (Table 2 ),

Table 2 (Case 1.) 24-hour sodium and potassium balance

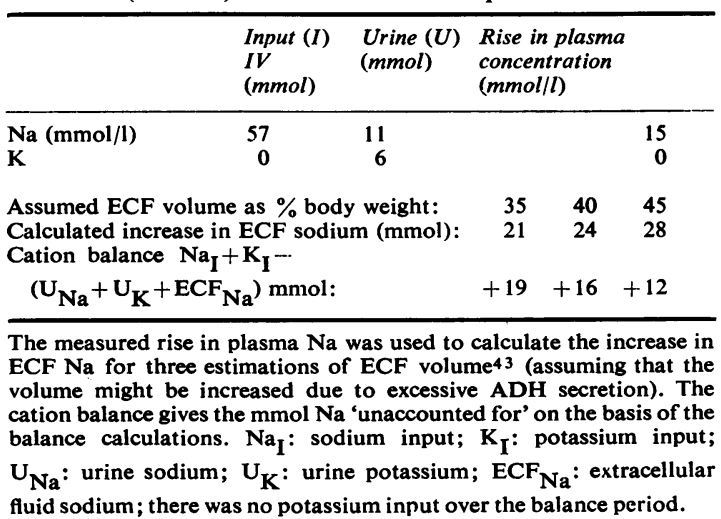

the degree of the discrepancy depending on the infant's extracellular fluid volume for which assumed values were used in the calculations. No stool was passed during this 24-hour balance period, neither was there evidence of gastrointestinal distension nor evidence of overt sweating. It seems probable therefore, that there took place a redistribution of the sodium administered to this infant from extracellular to intracellular compartments in exchange for potassium. In support of this view is the observation that Cases 2 and 3 were both in negative potassium balance and became hypokalaemic with continued urinary potassium loss. Continued natriuresis, which is a common feature of SIADH, was undoubtedly an additional factor responsible for the partial failure to restore plasma sodium to normal in Cases 1 and 2.

Pathogenesis of excessive ADH secretion. As a consequence of the pulmonary disease in these infants, several stimuli (Fig. 2) for excessive secretion of ADH may be present. It seems likely that the most important of these is a fall in left atrial tension, a potent cause of ADH secretion. ${ }^{1819}$ This might occur in situations where there is left atrial compression by markedly hyperinflated lungs, as in bronchiolitis and acute asthma, or when the fall in tension is a consequence of diminished left atrial filling secondary to a raised pulmonary vascular resistance ${ }^{4}$ as might occur in the above conditions or during the administration of CPAP or positive pressure ventilation.

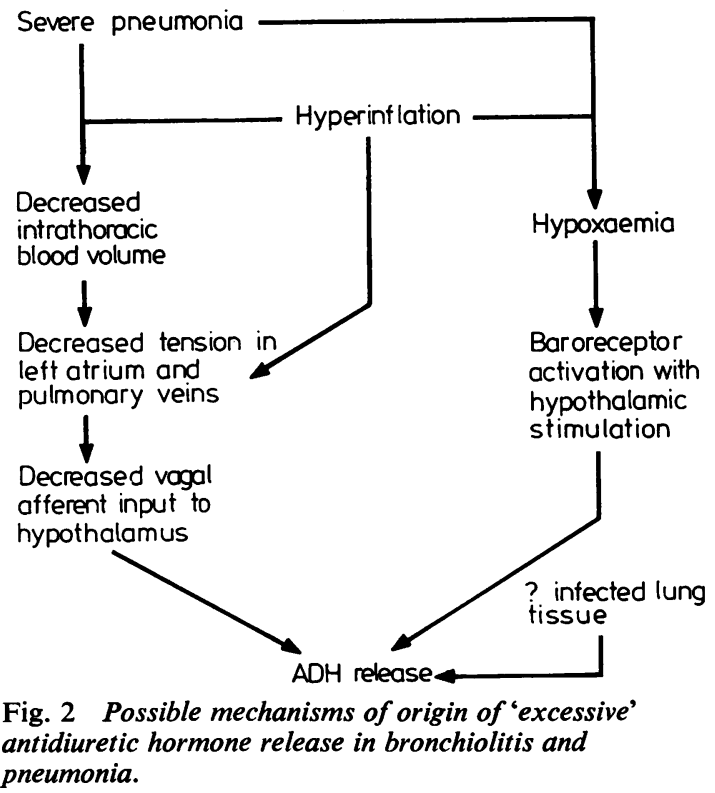


Such a reduction in left atrial tension, although being a consequence of regional factors, mimics the effect of systemic hypovolaemia by inducing ADH secretion. ${ }^{33}$

Also relevant is the observation that hypoxaemia causes release of $\mathrm{ADH}$ by direct hypothalamic stimulation in the fetal $\mathrm{lamb}^{34}$ and in anaesthetised dogs undergoing a water diuresis ${ }^{35}$ although, in addition, ADH release may be mediated via arterial baroreceptors. ${ }^{35}$

Whether ADH is actually secreted from virally infected lung tissue remains to be established. Tuberculous lung parenchyma has been shown to contain ADH, but it is not clear whether the ADHlike material is produced by the infected tissue or has been absorbed on to it from the plasma. ${ }^{36}$

In Cases 1 and 3 the duration of excessive secretion of $\mathrm{ADH}$ was brief. The initial, inappropriately high, urine concentration became normal during fluid restriction. In each case the improvement was associated with a rise in arterial oxygen tension although radiological evidence of pulmonary hyperinflation persisted for some days.

The clinical course of Case 2 was different. He maintained a high urine concentration for 5 days during which time small increases in fluid intake resulted in hyponatraemia. Throughout this period he was in positive sodium balance excluding possible losses in sweat (Fig. 1). On the seventh day of fluid restriction the urine specific gravity suddenly fell. It seems probable that there was excessive ADH secretion throughout this period causing water retention. The fact that the body weight remained stable despite increased metabolic needs (pyrexia, tachycardia, tachypnoea) while the baby was receiving a low calorie intake enforced by the fluid restriction, supports this view as does the observation that the body weight on recovery was some $250 \mathrm{~g}$ below the admission weight. Catabolism of this amount of body tissue to $\mathrm{CO}_{2}$ and water would have made a significant contribution to the total water 'load' in this baby. Continuing hypoxaemia was not the explanation for this infant's apparently prolonged excessive secretion of ADH. However, the degree of pulmonary hyperinflation in this infant was striking and this persisted throughout the period of presumed ADH secretion.

High plasma renin levels have been recorded during periods of fluid and sodium deprivation in SIADH $^{37}$ and in association with sodium deprivation in normal volunteers. ${ }^{38}$ Progressive hypertension developed in Case 2 during the phase of severe fluid restriction, and activation of the reninangiotension system might therefore have been the cause. ${ }^{39}$ At no time was there clinical or biochemical evidence (in the form of a metabolic acidosis) of reduced organ perfusion during the period of fluid restriction and increasing hypertension.

It is probable that rapidly developing hyponatraemia was the cause of the seizures in Cases 1 and 3 . Indeed the rapidity with which hyponatraemia can develop is well documented by the course of Case 2. In rats, hyponatraemia increases brain epileptogenicity. ${ }^{40}$

\section{Conclusions}

We suggest that routine sequential estimations be made of sodium and potassium concentrations and of osmolalities on plasma and urine samples during periods of deteriorating pulmonary function in infants with pneumonia or bronchiolitis. Avoidance of hypoxaemia may reduce the incidence of excessive ADH secretion; the value of instituting moderate fluid restriction with continued administration of sodium and potassium requirements remains to be investigated.

Sodium chloride administration, as a hypertonic solution, has been shown to be effective in achieving a rapid rise in plasma sodium in the short term despite associated high urine sodium concentrations, although in chronic inappropriate ADH secretion, fluid restriction with or without treatment with drugs ${ }^{41}$ remains the basis of treatment. Administration of frusemide may also be effective in treating the symptoms of acute hyponatraemia. ${ }^{42}$ The more aggressive forms of treatment are justified in the presence of marked hyponatraemia whether or not associated with convulsions. The development of hypertension may be a reflection of excessive fluid and sodium restriction.

Correction of hypoxaemia does not necessarily remove the stimulus for the inappropriate ADH secretion in cases of bronchiolitis with marked pulmonary hyperinflation.

We thank Dr M F Friedman and Dr J Luder for letting us have data on their patients, and Professor C J Dickinson for his help.

\section{References}

1 Darrow D C, Hartmann A F. Chemical changes occurring in the body as a result of certain diseases. IV. Primary pneumonia in children. Am J Dis Child 1929; 37: 323-34.

2 Rutstein D D, Thomson K J, Tolmach D M, Walker W H, Floody R J. Plasma volume and 'extravascular thiocyanate space' in pneumococcus pneumonia. J Clin Invest 1945; 24: 11-20.

3 Mor J, Ben-Galim E, Abrahamov A. Inappropriate antidiuretic hormone secretion in an infant with severe pneumonia. Am J Dis Child 1975; 129: 133-5. 
4 Cohen L F, di Sant'Agnese P A, Taylor A, Gill J R. The syndrome of inappropriate antidiuretic hormone secretion as a cause of hyponatremia in cystic fibrosis. $J$ Pediatr 1977; 90: 574-8.

5 Le Moing G, Gendrell D, Couvreur J, Gaultier Cl, Tournier G, Gerbeaux J. Sécrétion inappropriée d'hormone antidiurétique au cours des infections respiratoires aiguës à adénovirus chez l'enfant. Nouv Presse Med 1977; 6: 3825-33.

- Paxson C L, Jr, Stoerner J W, Denson S E, Adcock E W, III, Morriss F H, Jr. Syndrome of inappropriate antidiuretic hormone secretion in neonates with pneumothorax or atelectasis. J Pediatr 1977; 91 : 459-63.

7 Higer R W, Holliday M A. Acute bronchial asthma and possible inappropriate secretion of antidiuretic hormone (abstract). Pediatr Res 1973; 7: 428.

s Baker J W, Yerger S, Segar W E. Elevated plasma antidiuretic hormone levels in status asthmaticus. Mayo Clin Proc 1976; 51 : 31-4.

9 Pomarède R, Moriette G, Czernichow P, Relier J-P. Étude de la vasopressine plasmatique chez les enfants prematures soumis à las ventilation artificielle. Arch $\mathrm{Fr}$ Pediatr 1978; 35: Supplement 2, 75-83.

10 McQuillin J, Gardner P S. Rapid diagnosis of respiratory syncytial virus infection by immunofluorescent antibody techniques. Br Med J 1968; i: 602-5.

11 Sturdy P M, McQuillin J, Gardner P S. A comparative study of methods for the diagnosis of respiratory virus infections in childhood. J Hyg (Camb) 1969; 67: 659-70.

12 Karonen S-L, Morsky P, Siren M, Seuderling U. An enzymatic solid-phase method for trace iodination of proteins and peptides with 125-iodine. Anal Biochem 1975; 67: 1-10.

13 Chard T, Forsling M L. Bioassay and radioimmunoassay of oxytocin and vasopressin. In: Antoniades $\mathrm{H} \mathrm{N}$, ed. Hormones in human blood: detection and assay. Cambridge, Mass: Harvard University Press, 1976; 488-516.

14 Hays R M. Antidiuretic hormone. N Engl J Med 1976; 295: 659-65.

15 Verney E B. The antidiuretic hormone and the factors which determine its release. Proc R Soc Lond [Biol] 1947; 135: 25-106.

16 Haberich F J. Osmoreceptors in the portal circulation and their significance for the regulation of water balance. Triangle 1971; 10: 123-30.

17 Davies R, Forsling M L, Slater J D H. The inter-relationship between the release of renin and vasopressin as defined by orthostasis and propranolol. J Clin Invest 1977; 60: $1438-41$.

18 Gauer O H, Henry J P, Sieker H O. Cardiac receptors and fluid volume control. Prog Cardiovasc Dis 1961; 4: 1-26.

19 Goetz K L, Bond G C, Hermreck A S, Trank J W. Plasma ADH levels following a decrease in mean atrial transmural pressure in dogs. Am J Physiol 1970; 219: 1424-8.

20 Share L. Vasopressin, its bioassay, and the physiological control of its release. Am J Med 1967; 42: 701-12.

21 Schrier R W, Lieberman R, Ufferman R C. Mechanism of antidiuretic effect of beta adrenergic stimulation. $J$ Clin Invest 1972; 51: 97-111.

22 Berl T, Cadnapaphornchai P, Harbottle J A, Schrier R W. Mechanism of stimulation of vasopressin release during beta-adrenergic stimulation with isoproterenol. J Clin Invest $1974 ; 53$ : 857-67.

23 Orloff J, Handler J S. The cellular mode of action of antidiuretic hormone. Am J Med 1964; 36: 686-97.

24 Jamison $\mathbf{R}$ L, Maffly $\mathbf{R}$ H. The urinary concentrating mechanism. N Engl J Med 1976; 295: 1059-67.
${ }^{25}$ Schwartz W B, Bennett W, Curelop S, Bartter F C. A syndrome of renal sodium loss and hyponatremia probably resulting from inappropriate secretion of antidiuretic hormone. Am J Med 1957; 23 : 529-42.

26 Bartter F C, Schwartz W B. The syndrome of inappropriate secretion of antidiuretic hormone. Am J Med 1967; 42: 790-806.

27 Fichman M P, Bethune J E. The role of adrenocorticoids in the inappropriate antidiuretic hormone syndrome. Ann Int Med 1968; 68: 806-20.

28 Nolph K D, Schrier R W. Sodium, potassium, and water metabolism in the syndrome of inappropriate antidiuretic hormone secretion. Am J Med 1970; 49: 534-45.

29 Gonzalez C F, Finberg L, Bluestein D D. Electrolyte concentration during acute infections. Am J Dis Child 1964; 107: 476-82.

30 Edelman I S, Leibman J, O'Meara M P, Birkenfeld L W. Interrelations between serum sodium concentration, serum osmolality and total exchangeable sodium, total exchangeable potassium, and total body water. $J$ Clin Invest 1958; 37: 1236-56.

31 Jones N F, Barraclough M A, Forsling M L, Petch C P. Inappropriate production of vasopressin, potassium deficiency, and cerebrovascular disease. Am J Med 1968; 45: 474-9.

32 Kaye M. An investigation into the cause of hyponatremia in the syndrome of inappropriate secretion of antidiuretic hormone. Am J Med 1966; 41: 910-26.

33 Friedman A L, Segar W E. Antidiuretic hormone excess. J Pediatr 1979; 94: 521-6.

34 Alexander D P, Forsling M L, Martin M J, et al. The effect of maternal hypoxia on fetal pituitary hormone release in the sheep. Biol Neonate $1972 ; 21$ : 219-28.

${ }^{35}$ Anderson R J, Pluss R G, Berns A S, et al. Mechanism of effect of hypoxia on renal water excretion. $J$ Clin Invest 1978; 62: 769-77.

36 Vorherr H, Massry S G, Fallet R, Kaplan L, Kleeman C R. Antidiuretic principle in tuberculous lung tissue of a patient with pulmonary tuberculosis and hyponatremia. Ann Int Med 1970; 72: 383-7.

37 Skowsky W R, Fisher D A. Intermittent, idiopathic, inappropriate vasopressin secretion in a child. $J$ Pediatr 1973; 83: 62-8.

38 Brennan L A, Malvin R L. Concentrations of antidiuretic hormone in plasma during human sodium restriction. Nephron 1977; 19: 284-7.

${ }^{39}$ Skeggs L T, Dorer F E, Kahn J R, Lentz K E, Levine M. The biochemistry of the renin-antiotensin system and its role in hypertension. Am J Med 1976; 60: 737-48.

40 Swinyard E A, Toman J E P, Goodman L S. The effect of cellular hydration on experimental electroshock convulsions. $J$ Neurophysiol 1946; 9: 47-54.

41 Cherrill D A, Stote R M, Birge J R, Singer I. Demeclocycline treatment in the syndrome of inappropriate antidiuretic hormone secretion. Ann Int Med 1975; 83: 654-6.

42 Hantman D, Rossier B, Zohlman R, Schrier R. Rapid correction of hyponatremia in the syndrome of inappropriate secretion of antidiuretic hormone. Ann Int Med 1973; 78: 870-5.

43 Friis-Hansen B. Changes in body water compartments during growth. Acta Paediatr Scand [Suppl] 1957; 46: Supplement 110, 1-68.

Correspondence to Dr R P A Rivers, Department of Paediatrics, St Mary's Hospital Medical School, London W2 1PG.

Received 25 February 1980 